Document downloaded from:

http://hdl.handle.net/10251/55604

This paper must be cited as:

Herrero Cuco, C.; Llorens Agost, ML.; Oliver Villarroya, J.; Silva Galiana, JF.; Tamarit Muñoz, S. (2013). An empirical analysis of the influence of classmates on the academic performance. En Proceeding ITiCSE '13 Proceedings of the 18th ACM conference on Innovation and technology in computer science education. Association for Computing Machinery (ACM). 328-328. doi:10.1145/2462476.2465608.

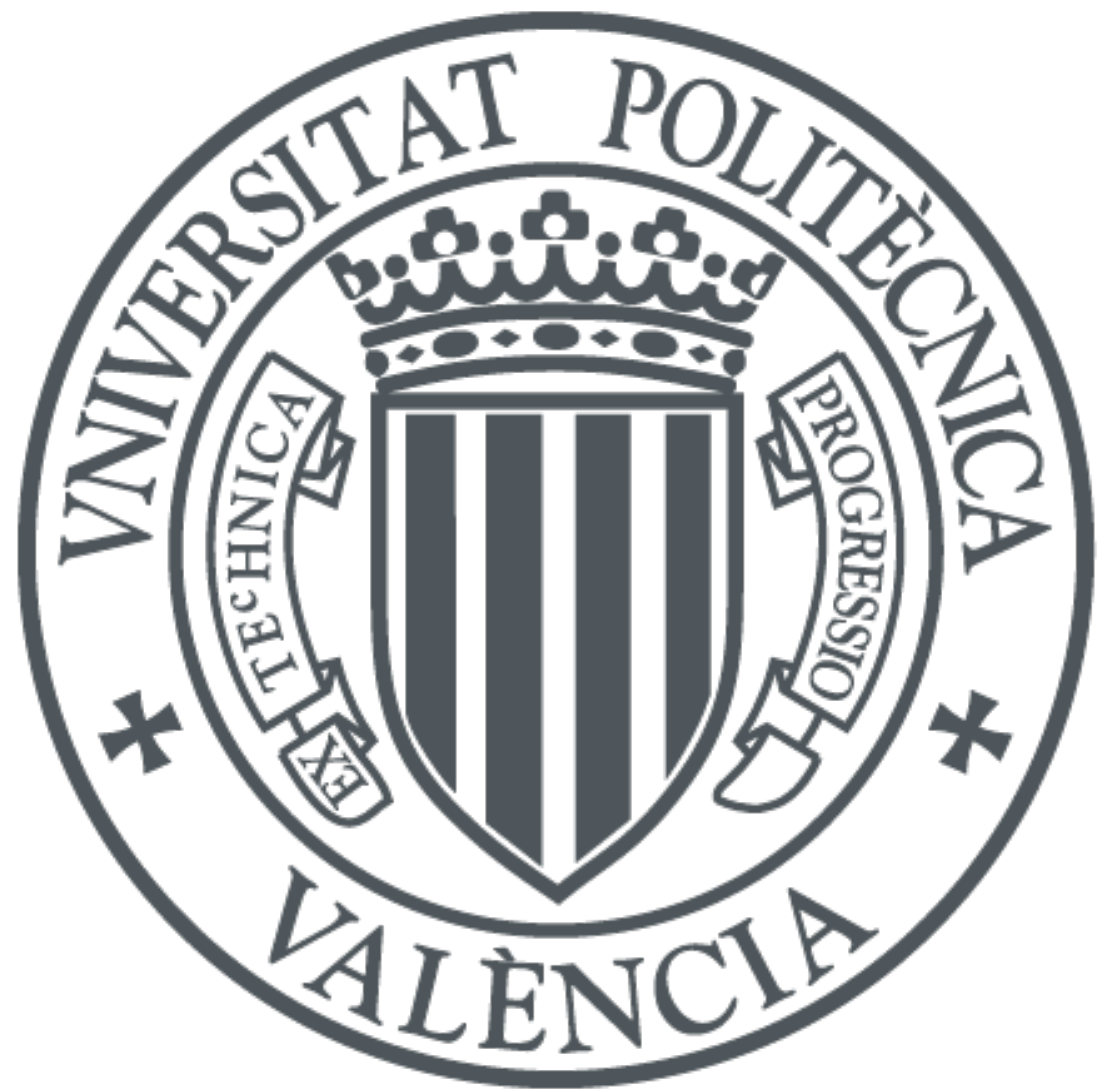

The final publication is available at

http://dx.doi.org/10.1145/2462476.2465608

Copyright Association for Computing Machinery (ACM)

Additional Information 


\title{
An Empirical Analysis of the Influence of Classmates on the Academic Performance
}

\author{
C. Herrero \\ cherrero@dsic.upv.es \\ M. Llorens \\ mllorens@dsic.upv.es \\ fjoliver@dsic.upv.es \\ J. Silva \\ jsilva@dsic.upv.es \\ S. Tamarit \\ stamarit@dsic.upv.es \\ Departament de Sistemes Informàtics i Computació \\ Universitat Politècnica de València \\ Camí de Vera, s/n. 46022 València, Spain
}

\begin{abstract}
This poster presents ongoing work that studies the influence of classmates over students' grades. We want to analyze different students habits and empirically quantify how they influence their academic performance. In particular, we want to answer the following questions: Do best/worst students sit together? Do students who sit alone get better grades than those who sit in pairs?
\end{abstract}

\section{Categories and Subject Descriptors}

K.3.2 [Computer and Information Science Education]: Computer science education, Information systems education

\section{Keywords}

Grades, classroom, attendance, productivity

\section{THE GOAL}

We collected data to study the influence of classmates on grades. In theoretical classes, we consider that a student sits in pairs if other student is sat by his/her left or right side. The students that sit in pairs in the lab are those who share a computer. Our current results already show a clear tendency that is interesting to discuss with other researchers.

\subsection{Do best/worst students sit together?}

In order to answer this question, we studied the grades of those students who sit together in lectures. The result, summarized in the figure, is overwhelming. Those students who formed steady pairs more than 14 times along the semester (consider that an academic semester has about 14 working weeks with two sessions per week) got grades with a difference in absolute value lower than one tenth. In general, those students that sit together get similar grades.

\subsection{Do students who sit alone get better grades than those who sit in pairs?}

For each student, we counted the number of times that she sat in pairs or alone. We classified a student as attending "alone" or "in pairs" if she attended alone or in pairs to at

Copyright is held by the author/owner(s).

ITiCSE'13, July 1-3, 2013, Canterbury, England, UK.

ACM 978-1-4503-2078-8/13/07.

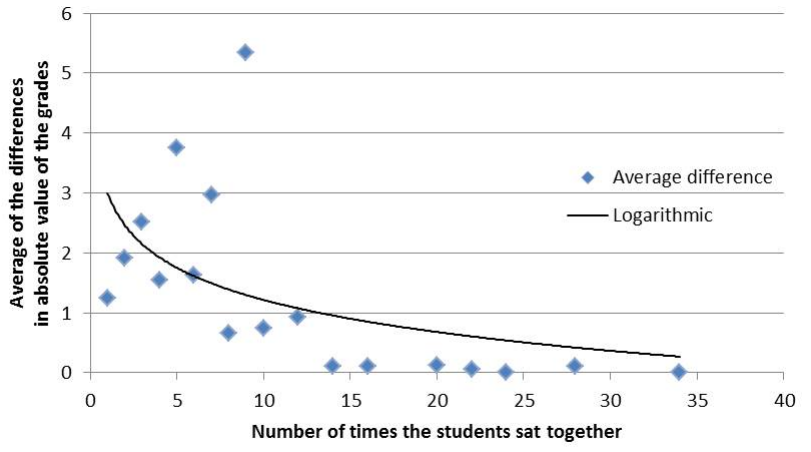

least $75 \%$ of the lectures. We analyzed the influence that being alone or in pairs has over the grades of the students and got the averages that can be seen in next table.

\begin{tabular}{|c|c|c|c|}
\cline { 2 - 4 } \multicolumn{1}{c|}{} & Theory & Practice & Global \\
\hline Alone & $+14.56 \%$ & $+5.35 \%$ & $+8.43 \%$ \\
\hline In Pairs & $-2.20 \%$ & $-5.96 \%$ & $-3.67 \%$ \\
\hline
\end{tabular}

We can see in the last column that, in general, students who sit alone get $12 \%(8.42 \%-(-3.67 \%))$ higher grades than students who sit in pairs. In fact, those students who usually sit in pairs get lower grades than the average. This phenomenon is even clearer in the theoretical classes, where there is a difference of almost $17 \%$.

\section{CONCLUSIONS}

These results answer the proposed questions in an empirical and quantified way. They provide a clear evidence that classmates do influence the students' grades. At this point, we want to get feedback from other researchers and discuss the way in which one can use these data to improve the learning process of students.

\section{ACKNOWLEDGMENTS}

This work has been partially supported by the Spanish MEC under grant TIN2008-06622-C03-02 and by the Generalitat Valenciana under grant PROMETEO/2011/052. Salvador Tamarit was partially supported by the Spanish MICINN under FPI grant BES-2009-015019. 